\title{
Soluble class I antigens in serum and CSF of patients with varicella-zoster virus meningitis
}

\author{
J C ALVAREZ-CERMEÑO,* J M ECHEVARRÍA, $\dagger$ L M VILLAR, I LÁZARO, \\ A BOOTELLO, P GONZÁLEZ-PORQUÉ
}

From the Departments of Neurology* and Immunology, Hospital Ramón y Cajal, Madrid and Department of Virology, $\dagger$ Instituto de Salud Carlos III, Majadahonda, Spain

SUMMARY Soluble class I antigens (sHLA) are secreted by lymphocytes upon activation in vitro. The intrathecal synthesis (ITS) of these molecules has been studied in patients with the varicella-zoster virus (VZV) meningitis. In this paper we describe a sHLA index IH = (CSF sHLA/serum sHLA): (CSF albumin/serum albumin) which is expected to increase only when sHLA is synthesised within the central nervous system (CNS). The IH is elevated in the first week of meningitis, when antibody synthesis is still low, and decreases thereafter. We think IH is an index of early lymphocyte activation within the CNS. The relation of these findings with previous in vitro studies is also discussed.

A soluble form of membrane-bound major histocompatibility complex (MHC) class I antigens (sHLA) has been shown to be secreted by both $\mathrm{T}$ and $\mathrm{B}$ lymphocytes when stimulated with mitogens. ${ }^{\prime}$

This is an early event and precedes lymphocyte DNA synthesis by 24 hours. ${ }^{2}$ To see whether this in vitro phenomenon has any significance in human pathology, we studied the intrathecal production of sHLA in a group of 16 patients with varicella-zoster virus (VZV) meningitis. We also report the relationship between the ITS of sHLA with local antibody synthesis, blood-brain barrier (BBB) function and time of evolution of the disease.

\section{Materials and methods}

\section{Patient selection}

We studied 16 acute aseptic meningitis (AAM) patients with demonstrated ITS of VZV-specific IgG antibodies. The detailed clinical data of eight of them as well as criteria for their selection have been previously reported. ${ }^{3}$ The 16 patients had fever, headache and signs of meningeal irritation. Cutaneous shingles were present at the onset of AAM or developed within a week in eight cases. The outcome was good with spontaneous remission of symptoms in each case.

One to three paired samples of serum and cerebrospinal

Correspondence to: $\mathrm{Dr} \mathrm{J}$ C Alvarez-Cermeño, Department of Neurology, Hospital Ramón y Cajal, Madrid, Spain.

Received 3 February 1989 and in revised form 20 April 1989. Accepted 9 June 1989 fluid (CSF) were obtained from each patient. The first sample was always collected within ten days of the onset of AAM and the second within one month. In two patients, a third pair was extracted 50 days and 41 days after the onset of symptoms. These samples were all kept at $-70^{\circ} \mathrm{C}$ unti assayed.

\section{Laboratory procedures}

Unconcentrated CSF and serum SHLA were measured by an ELISA method developed in our laboratory. ${ }^{4}$ Serum and CSF albumin were determined by single radial immunodifussion (Behring Institute FRG). To study the ITS of sHLA avoiding a possible influence of passively transferred serum molecules into CSF in the case of BBB damage, we calculated a sHLA index (IH), similar to that described for IgG. The ratio between the molecules in CSF and serum is related to the CSF albumin/serum ratio, which reflects the BBB status. IH is defined by the formula: $\mathrm{IH}=$ (CSF sHLA/Serum sHLA)/(CSF albumin/Serum albumin) where each parameter is expressed in milligrams per litre.

This quotient is expected to remain constant even if the BBB function changes, increasing only when sHLA is synthesised within the central nervous system (CNS). To establish the upper normal limit of IH, we calculated this value in 16 patients from a group with other neurologica diseases (OND) who suffered from non-specific headache and whose CSF and serum analyses were absolutely normal. Therefore we considered that values of IH above $9 \cdot 7$ (mean +2 SD of OND) indicate intrathecal synthesis of sHLA.

The measurement of specific IgG antibodies (Ab) to VZV, performed in CSF and sera using an indirect enzyme-linked immunoassay (ELISA) and the procedure to rule out other 
infections have been previously reported. ${ }^{3}$ We calculated two different indexes to evaluate the ITS of VZV-specific IgG within CNS. Antibody index A (ratio of CSF Ab titer/serum $\mathrm{Ab}$ titer to CSF albumin/serum albumin) ${ }^{6}$ and antibody index $\mathrm{B}$, which is defined as the ratio of CSF $\mathrm{Ab}$ titer/serum $\mathrm{Ab}$ titer to CSF total IgG/serum IgG.' The methods and results of VZV isolation techniques have been published elsewhere. ${ }^{3}$

Since our main purpose was the study of the ITS of SHLA, we divided the analytical data of our patients into two groups. Group A included CSF and sera data obtained within one week of the onset of AAM. The laboratory findings of samples studied after this first week of the disease constituted Group B of the data. All these studies were compared with those of the OND group.

Differences between means were tested with the rank-sum test. Correlations were compared with linear and non linear correlation analysis or Spearman's test.

\section{Results}

The table shows the main results of our study. Group A comprised nine analytical studies and Group B 21; serum sHLA was similar in OND and in patients with the AAM syndrome independently of the time of evolution of the disease. CSF sHLA is significantly increased in the first week of AAM $(p<0.01)$ and decreases thereafter $(p<0.05)$, although it remains elevated, when compared with OND $(p<0.05)$. As can be seen in the table, these changes are parallel to those of the BBB status as reflected by the CSF albumin/serum albumin quotient, which is very high in group $A(p<0.01)$, being almost normal in group $B$. As could be expected, there is a significant correlation between total CSF sHLA and albumin quotient ( $r$ $=0.80, \mathrm{p}<0.01$ ).

IH has a value of $4.02(0.74)$, mean (SEM) in OND group. In the first week of meningitis it rises threefold to $12.32(2.37)(\mathrm{p}<0.01)$ and decreases afterwards to $6.68(0.95)(p<0.05)$. There is a significant inverse linear correlation between $\mathrm{IH}$ and the number of days since the onset of symptoms $(r=-0.456, p<0.05)$. Interestingly, both $\mathrm{Ab}$ indexes were low the first week of AAM, and significantly elevated afterwards. No statistical correlation was found between IH and albumin quotient indicating that this index seems to be independent of BBB status.

\section{Discussion}

The presence of soluble Class I antigens (sHLA) in sera of different species is well documented. ${ }^{8-11}$ We have found these molecules in sera of normal human donors as well as in those of AIDS patients where its level is increased. ${ }^{4}$ These antigens are also present in CSF of OND and of patients with AAM. In the latter, sHLA are elevated in the first week of the disease decreasing thereafter. The establishment of a normal range for IH helped us to define that values above $9 \cdot 7$ reflect that sHLA are secreted within the central nervous system. Similarly to the IgG index, IH is independent of BBB status and this idea is corroborated by the absence of any statistical correlation between albumin quotient and IH.

We have found that IH is significantly increased in the first week of VZV meningitis, while intrathecal antibody synthesis is still low. IH decreases thereafter, with a significant inverse linear correlation with the time of evolution of the disease. At that time, ITS of antibodies against VZV increases fourfold as indicated by both the $\mathrm{Ab}$ indexes studied. These data have not been described before and we think they are the in vivo counterpart of the sHLA secretion that B and T lymphcytes produce in vitro upon stimulation, which precedes their maximal proliferation. ${ }^{12}$ We consider therefore that IH may be a reliable early index of lymphocyte activation within the central nervous system in patients with varicella-zoster virus meningitis.

This study was supported by a research grant from the Fondo de Investigaciones Sanitarias de la Seguridad Social.

Table CSF and serum data of VZV meningitis patients

\begin{tabular}{|c|c|c|c|}
\hline & OND group & $A A M$ group $A$ & $A A M$ group $B$ \\
\hline $\begin{array}{l}\text { N } \\
\text { Serum sHLA }(\mathrm{mg} / \mathrm{l}) \\
\text { CSF sHLA }(\mu \mathrm{g} / \mathrm{l}) \\
\text { Alb. quot. } \\
\text { IH } \\
\text { Ab index A } \\
\text { Ab index B }\end{array}$ & $\begin{array}{l}16 \\
1 \cdot 85,(0 \cdot 28) \\
32 \cdot 17,(6 \cdot 22) \\
5 \cdot 17,(0 \cdot 48) \\
4 \cdot 02,(0 \cdot 74) \\
0 \\
0\end{array}$ & $\begin{array}{l}9 \\
1 \cdot 65,(0 \cdot 21) \\
233 \cdot 22,(74 \cdot 11)^{*} \\
12 \cdot 35,(2 \cdot 8)^{*} \\
12 \cdot 32,(2 \cdot 37)^{*} \\
1 \cdot 33,(0 \cdot 58)^{* *} \\
3 \cdot 51,(1 \cdot 44)^{* *}\end{array}$ & $\begin{array}{l}21 \\
1 \cdot 56,(0 \cdot 13) \\
76 \cdot 52,(18 \cdot 69)^{* *}, \dagger \\
6 \cdot 97,(1 \cdot 45) \ddagger \\
6 \cdot 68,(0 \cdot 95)^{* *}, \dagger \\
5 \cdot 58,(1 \cdot 78)^{*}, \dagger \\
12 \cdot 01,(2 \cdot 34)^{*}, \ddagger\end{array}$ \\
\hline
\end{tabular}

Values are given as mean, (standard error of the mean). OND: Other neurological disease group. AAM group A: samples obtained within 7 days of the onset of VZV acute aseptic meningitis (AAM). AAM group B: samples obtained after the first 7 days of the disease.

Alb. quot.: CSF albumin/serum albumin $\times 0.001$

See under methods the description of antibody $(\mathrm{Ab})$ indexes.

$*$ * $<<0.05$ vs. OND

tp $<0.05$ vs. AAM group A 


\section{References}

1 Brieva JA, Villar LM, Cermeño JCA, et al. Major histocompatibility complex Class I antigens secretion by human lymphocytes (abstr). Faseb J, 1988;2:480.

2 Villar LM, Alvarez Cermeño JC, de la Sen ML, et al. Characterization of soluble Class I molecules present in human serum and spleen. Study of their secretion by lymphocytes in culture. Proc. Ninth European Immunology Meeting: Rome, 1988.

3 Echevarria JM, Martinez-Martin P, Tellez A, et al. Aseptic meningitis due to varicella-zoster virus: serum antibody levels and local synthesis of specific IgG, IgM and IgA. $J$ Infect Dis 1988;155:959-67.

4 Ferreira A, Villar LM, Alvarez-Cermeño JC, et al. Quantification of soluble serum HLA Class I antigens in healthy volunteers and AIDS patients. Clin Chim Acta 1988;174:207-12.

5 Tibbling G, Link H, Ohman S. Principles of albumin and IgG analyses in neurological disorders. I. Establish- ment of reference values. Scand J Clin Lab Infest 1977;37:385-90.

6 Arnadottir T, Reunanen M, Salmi A. Intrathecal $\$$ thesis of virus antibodies in multiple sclerosis patiegts. Infect Immun 1982;38:399-407.

7 Ukkonen P, Granstrom ML, Rasanen J, Salonen BM, Penttinen K. Local production of mumps IgG and IgM antibodies in the cerebrospinal fluid of meningtis patients. J Med Virol 1981;8:257-65.

8 Cosman D, Kress M, Khoury G, Jay G. Tissue-spe ific expression of an unusual H-2 (Class I) related gete. Proc Natl Acad Sci, USA 1982;79:4947-51.

$\overrightarrow{\overrightarrow{\vec{A}}}$

9 Spencer S, Fabre JM. Identification in rat liver and serem of water-soluble Class I MHC molecules possitily homologous to the murine Q10 gene product. $J$ Exp Med 1987;165:1595-608.

10 Pellegrino MA, Russo C, Allison J. HLA antigenspin human serum. Meth Enzymol 1984;108:624-6.

11 Krangel MS. Two forms of HLA Class I moleculeŝnin human plasma. Hum Immunol 1987;20:155-65. 